\title{
Modelling and simulation of a slurry bubble column reactor for green fuel production via hydrocracking of vegetable oil
}

\author{
Yuswan Muharam ${ }^{1, *}$, and Rizka Thalita Adevia ${ }^{1}$ \\ ${ }^{1}$ Department of Chemical Engineering, Faculty of Engineering, Universitas Indonesia, Depok 16424, Indonesia
}

\begin{abstract}
A slurry bubble column reactor to produce green fuel through hydrocracking of vegetable oil with $\mathrm{Ni}-\mathrm{W} / \mathrm{SiO}_{2}-\mathrm{Al}_{2} \mathrm{O}_{3}$ catalyst was simulated in this research with the objectives being to obtain a mathematical model of the reactor and an optimum operation condition. The steady state twodimensional axisymmetric model of the slurry bubble column reactor with the diameter of $2.68 \mathrm{~m}$ and height of $7.14 \mathrm{~m}$ was modelled by considering mass and heat transfers. The very small liquid superficial velocity reflects that the liquid phase is in batch-like operation. The gas of $0.01 \mathrm{~m} / \mathrm{s}$ in superficial velocity flows upward to suspend and agitate the spherical catalyst particles of $100 \mu \mathrm{m}$ in diameter inside the reactor. The reactor operated at 80 bar and $420^{\circ} \mathrm{C}$. Triglyceride of $5 \% \mathrm{w} / \mathrm{w}$ in dodecane and hydrogen of $105.5 \mathrm{~mol}$ hydrogen/triglyceride enter the reactor from the bottom. The research also considered pressure drop and loading catalyst distribution inside the reactor. Simulation results show that the triglyceride conversion is $99.26 \%$, the product yield is $40.68 \% \mathrm{w} / \mathrm{w}$, and the product purity is $45.55 \% \mathrm{w} / \mathrm{w}$.
\end{abstract}

\section{Introduction}

The production of fuel such as gasoline and diesel in industrial and transportation sectors really depends on crude oil. Along with population and economic growth, crude oil reserves are getting depleted, while energy demand continues to increase. The limited resources of fossil energy create a transition state to new and renewable energy that is more environmentally friendly as a necessity. Indonesia with abundant biodiversity has a high chance of overcoming the problem by producing green fuel, which is a second-generation renewable fuel. One of the high potential natural resources in Indonesia is jatropha curcas. Oil in its seeds is non-edible. Therefore, jatropha oil is more potential than its competitors such as palm oil and coconut oil, which are still widely used as edible oil. This oil can be processed into green fuel through hydroprocessing, i.e. a process of saturation (hydrotreating) and cracking (hydrocracking) of carbon chain.

Green fuel production through hydroprocessing of vegetable oils involves three phases. They are hydrogen $\left(\mathrm{H}_{2}\right)$ as gas phase, vegetable oil as liquid phase, and catalyst particles as solid phase. Therefore, a three-phase reactor is needed, such as trickle-bed reactor and slurry reactor. Slurry bubble column reactors have many advantages over trickle-bed reactors [1].

The catalyst used is a bifunctional catalyst, i.e. a combination of acidic catalyst and metallic catalyst for hydrogenation and cracking processes. Therefore, the reactor used is a multiphase reactor. Some of the technologies that have been used to produce green fuel from vegetable oil are UOP Renewable Jet Fuel
Process ${ }^{\mathrm{TM}}$, Nesto Oil NEXBTL Process, and Haldor Topsoe's HydroFlex ${ }^{\mathrm{TM}}$ [2].

Experimental and kinetic researches on green fuel production through hydroprocessing have been developed for several raw materials, such as second cooking oil [3] [4], refined, bleached, and deodorized palm oil (RBDPO) [5], and jatropha curcas [6].

There are only a few researches on modelling and simulation of hydroprocessing of vegetable oils [5] [7] [8] [9]. In fact, beside saving time and cost, researches on physicochemical modeling has been proven to give accurate results [10].

This research focuses on modelling of a slurry bubble column reactor to produce green fuel through hydrocracking of vegetable oil with $\mathrm{Ni}-\mathrm{W} / \mathrm{SiO}_{2}-\mathrm{Al}_{2} \mathrm{O}_{3}$ catalyst. The use of this reactor is based on its better temperature control than a trickle bed reactor [11]. The objectives of the researches are to obtain a mathematical model describing phenomena in the reactor, and to ascertain the behavior in the reactor.

\section{Modelling}

The system is a slurry bubble column reactor as illustrated in Figure 1. Hydrogen enters the reactor through a gas distributor (sparger) and triglycerides enters through an inlet hole, both at the bottom of the column. The reactor is filled with $\mathrm{Ni}-\mathrm{W} / \mathrm{SiO}_{2}-\mathrm{Al}_{2} \mathrm{O}_{3}$ catalyst. The inlet gas forms bubbles that move up and pass the slurry and provide agitation that keeps the solid catalysts evenly suspended in the liquid phase. Excess hydrogen and all of the products exit from the top of the reactor.

\footnotetext{
* Corresponding author: muharam@che.ui.ac.id
} 


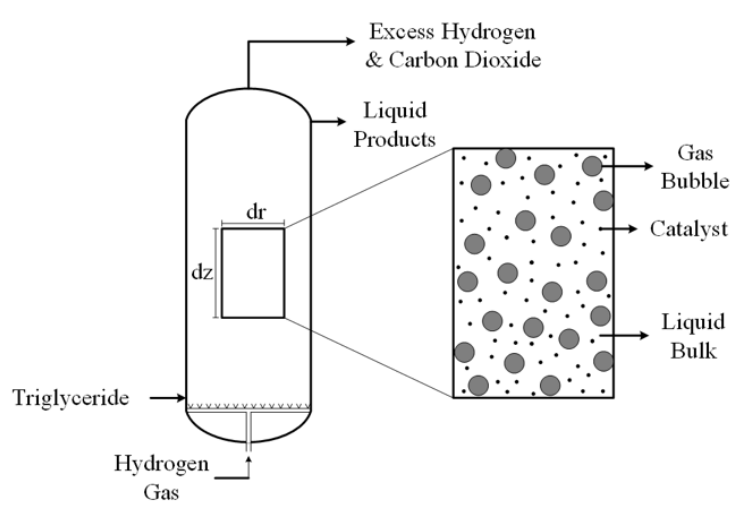

Fig. 1. Macroscale slurry bubble column reactor control volume.

The two-dimensional axisymmetric model of a slurry bubble column reactor as illustrated in Figure 2 was developed. The model considers pressure drop, mass transfer, catalysts distribution and heat transfer. The mass and heat balance take into account the transport in axial and radial direction. The pressure drop and catalysts distribution equations consider only the change in axial direction.

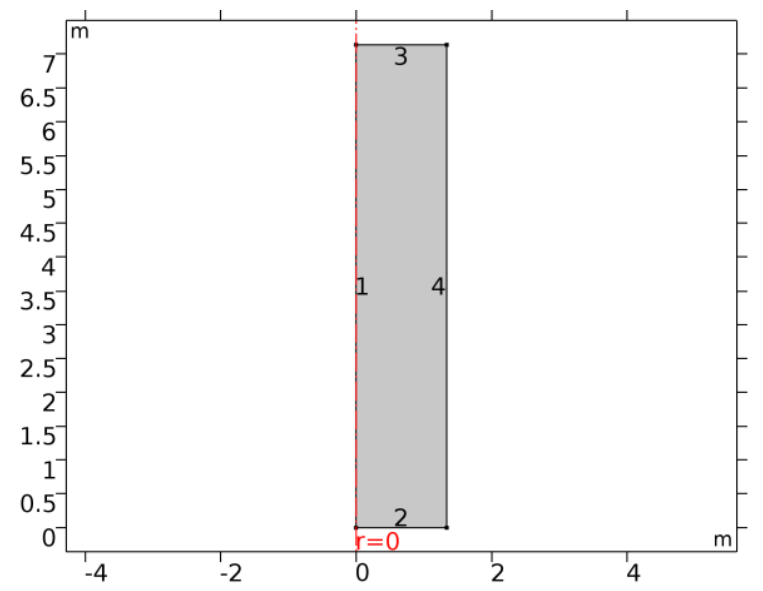

Fig. 2. 2D axisymmetric model of slurry bubble column reactor.

\subsection{Pressure drop}

In slurry bubble column reactor, pressure drop caused by friction can be neglected compared to the static height. The equation used to calculate the pressure drop is proposed by Schweitzer and Viguié (2009) [11] as Eq.(1):

$$
\frac{\partial P}{\partial z}=-\left(1-\varepsilon_{\mathrm{g}}\right) g \rho_{\mathrm{sl}}
$$

where $P$ is pressure, $\rho_{\mathrm{sl}}$ is the slurry density.

\subsection{Mass transfer}

A dispersion-convection model that encompasses firstorder irreversible kinetics of vegetable oil hydrocracking is presented in mass balance. This phenomenon, which characterize the fluid flow through porous media, is described by two differential equations of mass balance for each phase. The mass transfer resistances through the liquid-solid boundary layer and in the catalyst pores are negligible. Therefore, the concentration of species reacted or produced on the catalyst surface is equal to their concentration in the liquid phase. The overall reaction rate is controlled by the mass transfers in each phase, through gas-liquid boundary layer and the chemical reaction on the catalyst surface. Therefore, the mass balance for gas phase is as described in Eq.(2):

$$
\begin{aligned}
-D_{\mathrm{gz}} \varepsilon_{\mathrm{g}} \frac{\partial^{2} C_{i, \mathrm{~g}}}{\partial z^{2}}- & D_{\mathrm{gr}} \varepsilon_{\mathrm{g}} \frac{1}{r} \frac{\partial}{\partial r}\left(r \frac{\partial C_{i, \mathrm{~g}}}{\partial r}\right)+u_{\mathrm{gz}} \frac{\partial C_{i, \mathrm{~g}}}{\partial z} \\
& =R_{i, \mathrm{~g}-1}
\end{aligned}
$$

and mass balance for liquid-phase is as follows:

$$
\begin{gathered}
-D_{\mathrm{lz}} \varepsilon_{1} \frac{\partial^{2} C_{i, 1}}{\partial z^{2}}-D_{\mathrm{lr}} \varepsilon_{1} \frac{1}{r} \frac{\partial}{\partial r}\left(\mathrm{r} \frac{\partial C_{i, 1}}{\partial r}\right)+u_{\mathrm{lz}} \frac{\partial C_{i, 1}}{\partial z} \\
=-R_{i, \mathrm{~g}-\mathrm{l}}+r_{\mathrm{x}, i}
\end{gathered}
$$

Where $C_{i, \mathrm{~g}}$ and $C_{i, \mathrm{l}}$ are the gas-phase and liquid-phase concentration of component $i, u_{\mathrm{gz}}$ and $u_{\mathrm{lz}}$ are the axial gas and liquid superficial velocity, $\varepsilon_{\mathrm{g}}$ and $\varepsilon_{\mathrm{l}}$ are the gas and liquid holdup, $R_{i, \mathrm{~g}-1}$ is the gas-liquid mass transfer rate of component $i$, and $r_{\mathrm{x}, i}$ is the chemical reaction of component $i$. The axial and radial gas-phase mixing is expressed by dispersion coefficient $D_{\mathrm{gz}}$ and $D_{\mathrm{gr}}$. The axial and radial liquid-phase mixing is expressed by dispersion coefficient $D_{\mathrm{lz}}$ and $D_{\mathrm{lr}}$.

\subsection{Catalysts distribution}

In the slurry bubble column reactor, the catalyst loading varies along the reactor height. This catalyst loading is included in the kinetic rate equations. The equation used to describe catalysts distribution is as follows [12] [13]:

$$
W=\bar{W} B o_{\mathrm{s}} \mathrm{e}^{\left(-B o_{\mathrm{s}} \xi\right)}\left(1-\mathrm{e}^{-B o_{\mathrm{s}}}\right)^{-1}
$$

Where $\bar{w}$ the average catalyst distribution, $B o_{\mathrm{c}}$ is the catalyst Bodenstein number, $\xi$ is ratio of $z$ position to the reactor length.

\subsection{Heat transfer}

For heat transfer, a convection-conduction model is presented. The temperature of gas, liquid, and solid phases is assumed to be at thermal equilibrium. The heat balance is written in Eq.(5):

$$
-k_{\mathrm{eff}}\left[\frac{1}{r} \frac{\partial}{\partial r}\left(r \frac{\partial T}{\partial r}\right)+\frac{\partial^{2} T}{\partial z^{2}}\right]+\rho C_{\mathrm{p}} U_{\mathrm{z}} \frac{\partial T}{\partial z}=Q
$$

Where $T$ is temperature, $k_{\text {eff }}$ is the effective thermal conductivity, $C_{\mathrm{p}}$ is the slurry heat capacity and $Q$ is the reaction heat.

\subsection{Boundary condition}

At axial symmetry of the reactor (boundary 1 in Figure 2), symmetry boundary is applied for mass and heat transfers. At the reactor inlet (boundary 2 in Figure 2), Dirichlet boundary condition, which is the inlet temperature, is 
specified for heat transfer, and Danckwerts boundary is for mass transfer. In Danckwerts boundary mass flux entering point $z=0$ (inlet of the reactor) is solely due to the convective flow. Mass flux leaving point $z=0$ is due to the convective flow and dispersion. At the reactor outlet (boundary 3 in Figure 2), the boundary condition is dominated by convective flux for each phase. At the reactor wall (boundary 4 in Figure 2), the boundary condition applied for mass transfer is no flux, meanwhile for heat transfer, the applicable boundary condition is conductive flux due to heat exchange between the reactor wall and the bed.

\section{Results and Discussion}

Vegetable oil in this study is jatropha oil represented by triglycerides. The reaction mechanism (as shown in Figure 3) and kinetic model is adopted from Anand et al. [6]. The reactor operates under steady-state condition and its model is simulated numerically with the process and geometry parameters as shown in Table 1 .

Table 1. Process and geometry parameters for simulation.

\begin{tabular}{|l|c|}
\hline \multicolumn{1}{|c|}{ Parameter } & Value \\
\hline Reactor diameter & $2.68 \mathrm{~m}$ \\
\hline Reactor height & $7.14 \mathrm{~m}$ \\
\hline Catalyst diameter & $100 \mu \mathrm{m}$ \\
\hline Superficial gas velocity & $0.01 \mathrm{~m} / \mathrm{s}$ \\
\hline Inlet pressure & $80 \mathrm{bar}$ \\
\hline Inlet temperature & $693 \mathrm{~K}$ \\
\hline Inlet molar ratio of $\mathrm{H}_{2} / \mathrm{TG}$ & $105.5 \mathrm{~mol} / \mathrm{mol}$ \\
\hline Inlet TG fraction & $5 \% \mathrm{w} / \mathrm{W}$ \\
\hline Wall temperature & $420^{\circ} \mathrm{C}$ \\
\hline
\end{tabular}

Figure 4 shows the pressure profile in the reactor. The pressure slightly decreases toward the reactor outlet. The total pressure drop due to the static height is about 0.188 bar. Such small value is one of the advantages of using slurry bubble column reactor for a three-phase system.

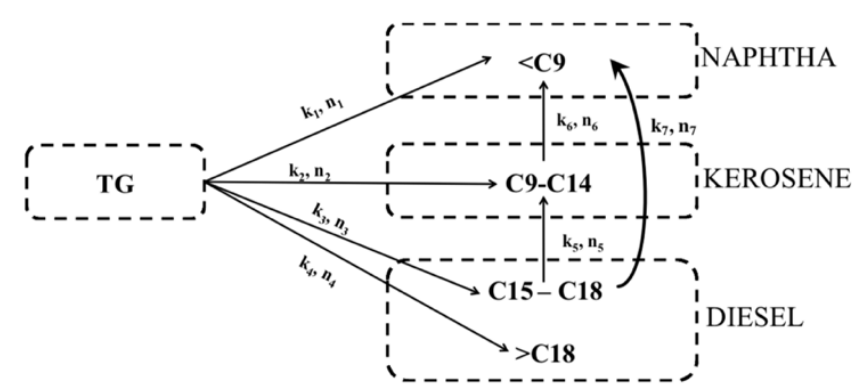

Fig. 3. Hydrocracking reaction mechanism [5].

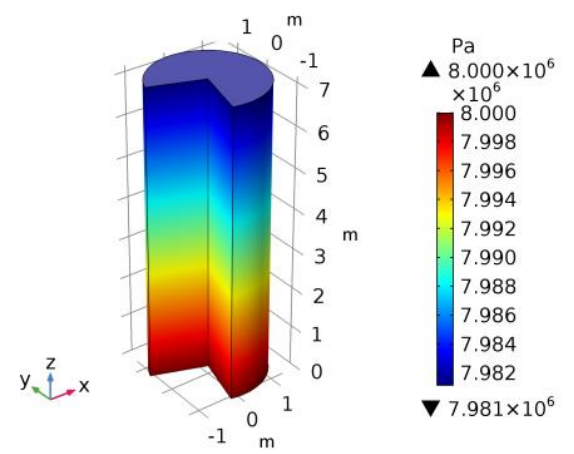

Fig. 4. Pressure profile.

The reactant components are triglyceride and hydrogen. The product are hydrocarbon and carbon dioxide. The hydrocarbon product is divided into four categories, i.e. diesel $\left(\mathrm{C}_{17} \mathrm{H}_{36}\right)$, kerosene $\left(\mathrm{C}_{9} \mathrm{H}_{20}\right.$ and $\left.\mathrm{C}_{11} \mathrm{H}_{24}\right)$, naphtha $\left(\mathrm{C}_{3} \mathrm{H}_{8}, \mathrm{C}_{6} \mathrm{H}_{14}\right.$, and $\left.\mathrm{C}_{8} \mathrm{H}_{18}\right)$, and wax $\left(\mathrm{C}_{19} \mathrm{H}_{40}\right)$. The expected green fuel component that used to measure reactor performance are diesel, kerosene, and naphtha.

The triglycerides (TG) concentration decreases in the axial direction as shown in Figure 5 (a). This is due to the fact that hydrocracking reactions consumes $\mathrm{TG}$ and convert it into green fuel products. The nearly flat axial profile indicates that the mixing in the liquid phase takes place very well. In fact, the radial profile is practically flat.

The hydrogen concentration decreases in the gasphase and increases in the liquid-phase as shown in Figure 5 (b) and 5 (c). Hydrogen enters the reactor as gas. On its traveling in the reactor some hydrogen molecules transport to the liquid phase. Figure 5 (b) and 5 (c) show

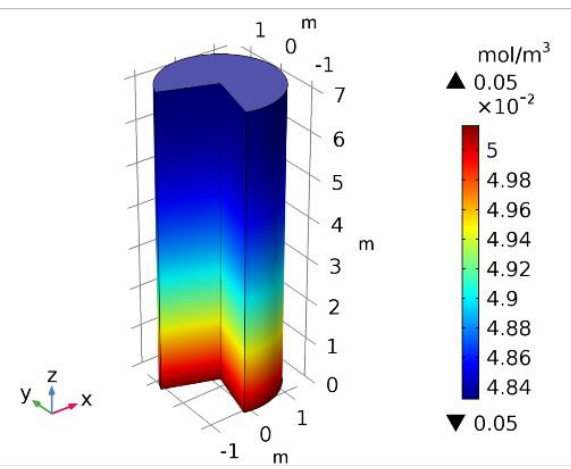

(a)

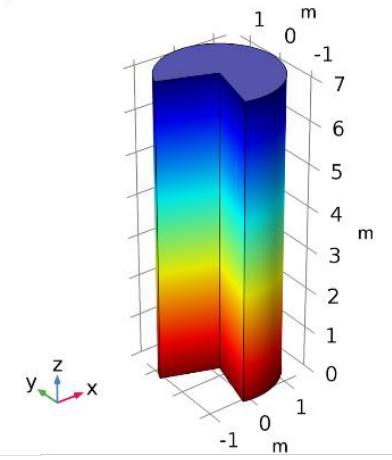

(b)
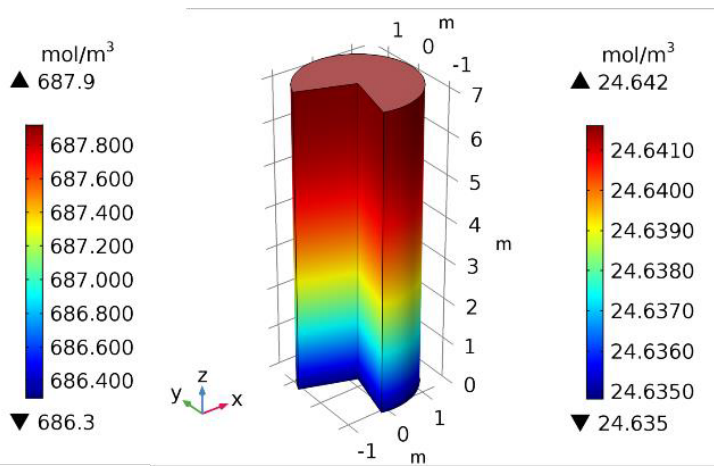

(b)

Fig. 5. Reactants concentration profile: (a) triglyceride, (b) hydrogen in gas phase, (c) hydrogen in liquid phase 


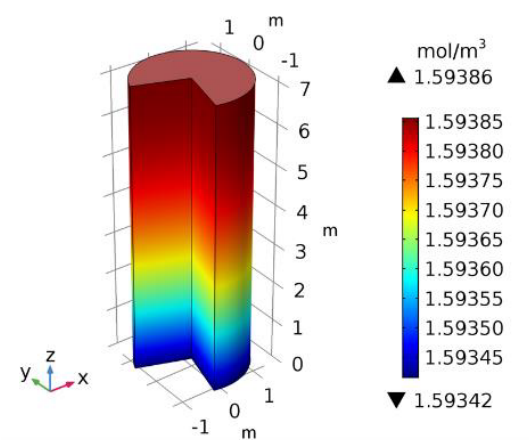

(a)

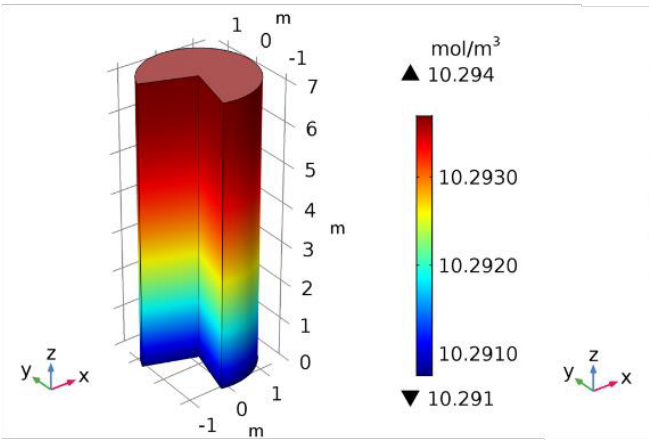

(d)

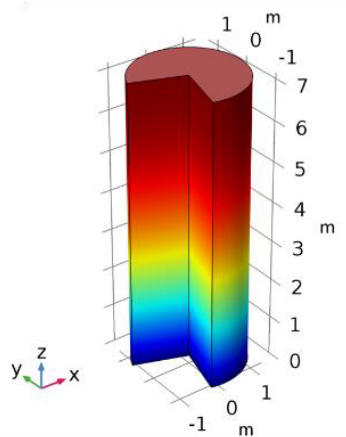

(b)

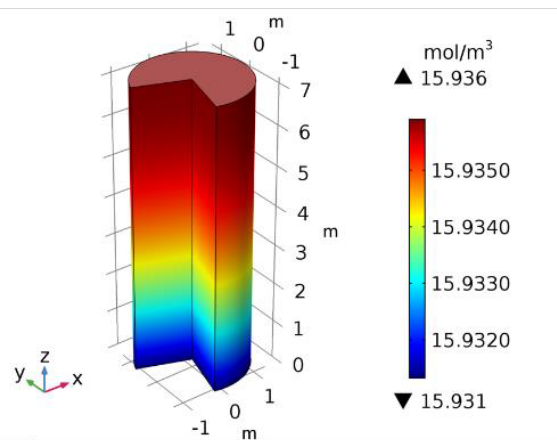

(c)

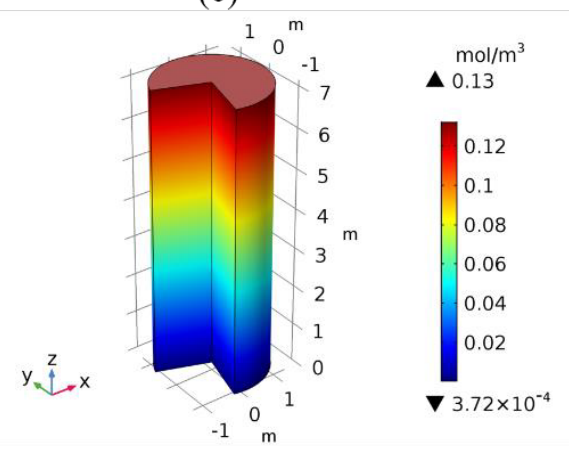

(f)

Fig. 6. Products concentration profile: (a) diesel, (b) kerosene, (c) naphtha, (d) wax, (e) carbon dioxide in liquid phase, (f) carbon dioxide in gas phase.

that hydrogen in the gas phase always transport from the gas phase to the liquid phase since there is a concentration gradient between the gas phase and the liquid phase in every spatial position in the reactor. The increasing concentration of hydrogen in the liquid phase is also caused by much lower reaction rate when compared to the mass transfer rate from the gas phase to the liquid phase.

Figure 6 shows the product profile in the gas phase and the liquid phase. The concentration of all products in the liquid phase increase along the reactor. The products are dominated by naphtha with the highest concentration being $15.936 \mathrm{~mol} / \mathrm{m}^{3}$ at the outlet of the reactor. This conforms with the reaction mechanism where it manages to produce naphtha more than the others. Naphtha can be produced through direct cracking of TG and advanced cracking of diesel and kerosene.

The carbon dioxide concentration in the liquid phase is higher than in the gas phase since the mass transfer resistance by gas-liquid boundary layer restrains carbon dioxide molecules to transport to the gas phase. In contrast to hydrogen, the increasing concentration of carbon dioxide in the gas phase along the reactor is caused by the fact that its reaction rate is greater than its mass transfer rate from the liquid phase to the gas phase.

Figure 6 (e) and (f) show that carbon dioxide always transports from the liquid phase to the gas phase since there is a concentration gradient between the liquid phase and the gas phase in every spatial position in the reactor.

The catalyst particle distribution in the reactor exhibits in Figure 7. In general, the catalyst particles are almost evenly distributed throughout the reactor. The higher catalyst concentration occurs near the bottom (inlet) of the reactor. This is due to the fact that the precipitation velocity of solid particles in a large swarm is higher than the liquid phase resistance [14]. The very low difference in the catalyst concentration in axial direction has no significant effect on the triglyceride consumption rate since the temperature slightly increases in axial direction.

The temperature profile throughout the reactor is shown in Figure 8. The exothermic reaction heat heats the reactor content so the temperature rises. The increasing temperature above its optimum condition leads to poor performance. In this study, the reaction heat was removed by externally cooling. The reactor wall was set at the same temperature as the feed fluid temperature $(693 \mathrm{~K})$. The simulation results show that the temperature increases from the inlet to the outlet due to the reaction with the difference being about $4 \mathrm{~K}$, as shown in Figure 8. This confirms the theory that due to its good mixing property a slurry bubble column reactor offers a relative ease of heat removal with less cooling area than some other types

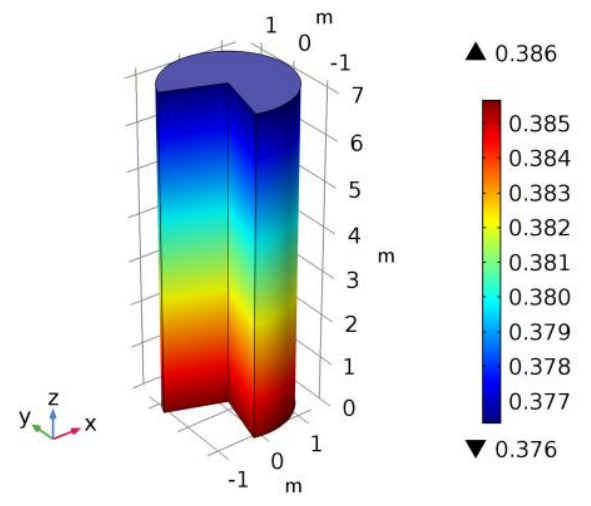

Fig. 7. Catalyst particle distribution. 


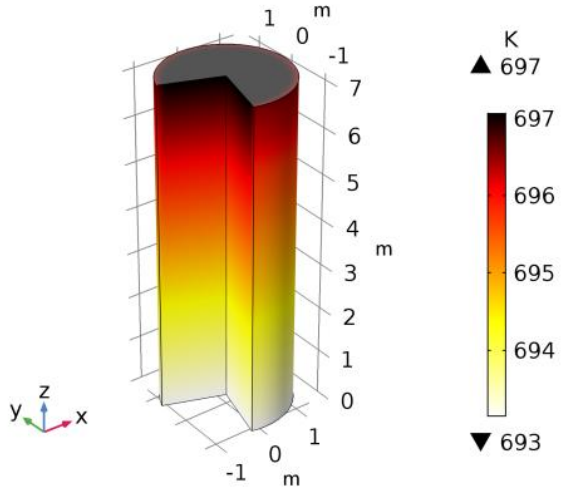

Fig. 8. Temperature profile.

The reactor performance is measured by the triglyceride conversion, the green fuel yield, and the green fuel purity. This performance is shown in Table 2. It can be seen in the table that the chemical reactions take place very well. The triglyceride conversion is very high, i.e. $99.26 \%$. It happens because an excessive hydrogen gas was set in the chemical kinetics, so triglyceride acts as the limiting reactant. However, the green fuel yield and the green fuel purity are still poor. This confirms the reaction mechanism which tells that the rates of byproduct formation, i.e. wax, are dominated.

Table 2. Reactor performance parameter

\begin{tabular}{|c|c|}
\hline Parameter & Value \\
\hline Triglyceride conversion & $99.26 \%$ \\
\hline Yield & $40.68 \% \mathrm{w} / \mathrm{w}$ \\
\hline Purity & $45.55 \% \mathrm{w} / \mathrm{w}$ \\
\hline
\end{tabular}

\section{Conclusion}

The model of a slurry bubble column reactor for green fuel production by hydrocracking of vegetable oil has been developed. The simulation results confirm the advantages of a slurry bubble column reactor where the pressure drop is low and the temperature is easy controlled. Simulation results show that the triglyceride conversion is $99.26 \%$, the green fuel yield is $40.68 \% \mathrm{w} / \mathrm{w}$, and the green fuel purity is $45.55 \% \mathrm{w} / \mathrm{w}$.

We express our gratitude to the University of Indonesia, which funded this research through the Hibah Publikasi Internasional Terindeks untuk Tugas Akhir Mahasiswa scheme under the contract No 2573/UN.2.R3.1/HKP.05.00/2018.

\section{References}

1. L. Sehabiague, R. Lemoine, A. Behkish, Y. J. Heintz, M. Sanoja, R. Oukaci and B. I. Morsi, "Modeling and Optimization of a Large-scale Slurry Bubble Column Reactor for Producing $10,000 \mathrm{bbl} /$ day of Fischer-Tropsch Liquid Hydrocarbons," Journal of the Chinese Institute of Chemical Engineers, vol. 39, pp. 169-179, (2008)
2. R. Sotelo-Boyás, F. Trejo-Zárraga and F. d. J. Hernández-Loyo, "Hydroconversion of Triglycerides into Green Liquid Fuels, Chapter:8," in Hydrogenation, I. Karamé, Ed., InTech, (2012), pp. 187-211.

3. Y.-S. Ooi, R. Zakaria and A. R. Moham, "Catalytic Cracking of Used Palm Oil and Palm Oil Fatty Acids Mixture for the Production of Liquid Fuel: Kinetic Modeling," Energy \& Fuels, vol. 18, pp. 1555-1561, June (2004).

4. W. Charusiri and T. Vitidsant, "Kinetic Study of Used Vegetable Oil to Liquid Fuels over Sulfated Zirconia," Energy \& Fuels, vol. 19, pp. 1783-1789, May (2005).

5. J. F. V. Manco, "Conceptual Design of a Palm Oil Hydrotreatment Reactor for Commercial Diesel Production," Universidad Nacional de Colombia, Medellín, Colombia, (2014).

6. M. Anand, S. A. Farooqui, R. Kumar, R. Joshi, R. Kumar, M. G. Sibi, H. Singh and A. K. Sinha, "Kinetics, thermodynamics and mechanisms for hydroprocessing of renewable oils," Applied Catalysis A: General, vol. 516, pp. 144-152, (2016).

7. A. A. Forghani, M. Jafarian and P. Pendleton, "Mathematical modelling of a hydrocracking reactor for triglyceride conversion to biofuel: model establishment and validation," International Journal of Energy Research, vol. 38, pp. 16241634, July (2014).

8. Y. Muharam, O. A. Nugraha, and D. Leonardi "Modelling of a Hydrotreating Reactor to Produce Renewable Diesel from Non-Edible Vegetable Oils ," Chemical Engineering Transactions, 56, 15611566 (2017).

9. A. S. Wirya, "Pemodelan Trickle Bed Reactor untuk Hydrocracking Minyak Jarak menjadi Green Fuel," Universitas Indonesia, Depok, (2017).

10. L. Attanatho, "Performances and Kinetic Studies of Hydrotreating of Bio-Oils in Microreactor," Oregon State University, Corvallis, 2012.

11. A. Gianetto and V. Specchia, "Trickle-Bed Reactors: State of Art and Perspectives," Chemical Engineering Science, vol. 47, no. No. 13/14, pp. 3197-3213, (1992).

12. J. Schweitzer and J. Viguié, "Reactor Modeling of a Slurry Bubble Column for Fischer-Tropsch Synthesis," Oil \& Gas Science and Technology Rev. IFP, vol. 64, no. 1, pp. 63-77, (2009).

13. E. J. Farkas and P. F. Leblond, "Solids concentration profile in the bubble column slurry reactor," The Canadian Journal of Chemical Engineering, vol. 47, pp. 215-217, 1969.

14. N. A. Ali, "Simulation of Gas-to-Liquid (GTL) Process in Slurry Bubble Column Reactor," University of Technology, Iraq, 2008.

15. Y. Muharam and A. Kurniawan, "Computational Fluid Dynamic Application in Scale-up of a Stirred- 
batch Reactor for Degumming Crude Palm Oil," International Journal of Technology, vol. 7(8), pp. 1344-1351, 2016. 